\title{
Reliability of Main Event Measurement in the Discourse of Individuals with Aphasia
}

The purpose of this study was to: (a) compare the performance of healthy adults and adults with aphasia on ability to convey main events in pictured stimuli and (b) establish session-to-session reliability of the authors' main event measure. The main event measure was designed to quantify participants' abilities to convey an understanding of the central relationships between concepts depicted in pictured stimuli. Participants were older adults with and without brain damage. Results indicated that healthy adults told a significantly higher proportion of main events than adults with aphasia and that for both groups, the main events measure was stable across sessions. 


\section{Reliability of Main Event Measurement in the Discourse of Individuals with Aphasia}

\section{$\underline{\text { Introduction }}$}

Quantitative measures of the structured discourse skills of adults with aphasia can be valuable in documenting evidenced-based practice. A number of studies have shown that measures such as Yorkston and Beukelman's (1980) content unit analysis and Nicholas and Brookshire’s (1993) correct information unit (CIU) analysis are helpful in monitoring changes in the connected speech of individuals with aphasia (Yorkston \& Beukelman, 1980; Craig et al., 1993; Nicholas \& Brookshire, 1993). Moreover, research suggests that any comprehensive assessment of structured discourse should also include a measure of the ability to relay main events (Capilouto, Wright \& Cranfill, 2003; Nicholas \& Brookshire, 1995).

Van Dijk and Kintsch (1983) have suggested that one way speakers establish main ideas in conversational discourse is by communicating the relations and causal links among units of information. In keeping with that idea, Wright, Capilouto, Wagovich, Cranfill \& Davis (in press) developed a main event measure designed to focus on an individual's ability to convey the relationships and causal connections between ideas. Participants were younger and older healthy adults. Following a priori review of a series of picture stimuli (Nicholas \& Brookshire, 1993), a list of main events for each, and participants’ narratives were measured against the a priori lists. Results indicated that the main events analysis developed in the study was stable within participants across time. Results further suggested that for the older group, content information units and the proportion of main events told appeared to measure different aspects of discourse. This finding adds support to the notion that main event analysis is a critical component of any comprehensive assessment of discourse. 
What is lacking in the previous investigations is (a) data pertaining to the relative performance of adults with aphasia on the main event measure and (b) session to session stability of the measure with adults with aphasia. The purpose of the present investigation, then, is two-fold. The first objective was to compare the performance of healthy adults and adults with aphasia in their ability to convey main events in pictured stimuli. By including adults with and without brain damage, the intent was to collect data on a measure of discourse that can then be used as a comparative reference when evaluating the discourse abilities of adult clinical populations. The second objective was to establish session-to-session stability of the main event measure with adults with aphasia.

\section{Method}

\section{$\underline{\text { Participants }}$}

Participants were eight adults with aphasia (APH; 5 females, 3 males), at least three months post stroke, and eight neurologically intact adults (NI; 6 females, 2 males). Participants with aphasia ranged from mild to moderate in severity as determined by their performance on the Western Aphasia Battery (WAB; Kertesz, 1982). Aphasia quotients from the WAB were computed for participants $(\underline{\mathrm{M}}=71.6, \underline{\mathrm{SD}}=19.9)$. The NI participants completed the Mini-Mental Status Examination (MMSE; Folstein, Folstein, \& McHugh, 1975), a cognitive screening measure, and received scores of 26 or higher $(\underline{\mathrm{M}}=28.4, \underline{\mathrm{SD}}=2.2)$. The NI and APH groups did not differ significantly in age, $\mathrm{F}(1,14)=.34, \mathrm{p}=.57$, or years of education completed, $\mathrm{F}(1,14)=$ $.13, \mathrm{p}=.73$. See Table 1 for group demographics.

\section{Language Elicitation and Transcription}

Participants' language samples consisted of their storytelling of the two single pictures and two picture sequences from Nicholas and Brookshire (1993). The single pictures each depict 
multiple events that can be developed, with some degree of inference, into a narrative. The picture sequences each consist of six frames depicting a related sequence of activities. In presenting the stimuli, the examiners followed Nicholas and Brookshire's (1993) instructions. For all stimuli, participants were asked to talk about what was going on in the picture(s). If a participant stopped after 15 seconds or less, he or she was prompted with “Can you tell me more?” No other instructions were given. These procedures were repeated for each picture or picture sequence in both sessions. The samples were audio recorded then orthographically transcribed.

\section{Language Analysis: Proportion of Main Events}

As a measure of the content of participants' storytelling, each sample was evaluated for the proportion of main events included. A main event was operationally defined as an event that was (a) of sufficient importance to the story as a whole and (b) independent from the other events in the story (Wright et al., in press). A complete list of the main events for each set of stimuli, as well as detailed information about the method of deriving the lists of main events, is presented in Wright et al. (in press).

$\underline{\text { Procedures }}$

Participants attended two sessions occurring approximately two weeks apart. During the first, participants provided their demographic and medical history information. The participants with aphasia completed the WAB, and the NI participants completed the MMSE. The first set of elicited narratives was also collected. During the second session, participants completed the narrative task a second time. Order of picture presentation was randomized across participants and sessions. 


\section{$\underline{\text { Results }}$}

\section{Group Differences}

A mixed analysis of variance (ANOVA) of group (APH, NI) by picture stimulus type (single, sequence) by session (Session 1, Session 2) was conducted to determine a) group differences in proportion of main events told and b) effect of picture stimuli type. Preliminary results indicate that the group main effect approached significance, $F(1,14)=3.93$, $p=.07$, with the NI group producing a higher proportion of main events compared to the APH group. The picture stimulus type main effect was statistically significant, $F(1,14)=14.00, p<.01$; participants yielded a higher proportion of main events for the sequence pictures than the single pictures. The session main effect and interactions were not significant. See Table 2 for groups’ data for proportion of main events told.

Post hoc analyses were conducted to determine if groups differed in proportion of main events told for each picture stimulus type. Preliminary results indicate that the NI group told a significantly higher proportion of main events for the single pictures, $F(1,30)=7.48, p<.05$, and sequence pictures, $\mathrm{F}(1,30)=6.23$, $\mathrm{p}<.05$, than the APH group.

\section{Session-to-Session Reliability}

Reliability of the measures was determined two ways: (a) absolute value of the change in performance from Session 1 to Session 2, and (b) Pearson correlations between Session 1 and Session 2 (See Table 3). For both groups, the main events measure was stable across sessions; that is, a significant Pearson correlation was found for the APH group, $\mathrm{r}=.82$, and NI group, $\mathrm{r}=$ .72 at $\mathrm{p}<.01$. 


\section{Conclusions and Implications of the Study}

Results of preliminary analyses suggest that adults with and without aphasia may differ on this quantitative measure of discourse. If so, this finding would be of clinical relevance because it provides some evidence of validity for the use of the authors' main events measure with individuals with aphasia. Results also suggest that this procedure is stable across time for this population. This finding is equally important in that stable measures enable pre- and post treatment testing. Finally, the proportion of main events provided by participants differed significantly for each picture type (i.e., single picture, sequential pictures). More main events were provided in response to sequential picture stimuli, compared to single picture stimuli. These findings are consistent with those of Wright et al. (in press), for adults with normal language, and they suggest that greater inferencing is needed to derive a story from a single picture than from a sequence of pictures. Clinical implications regarding use of the main events measure will be discussed in further detail. 


\section{$\underline{\text { References }}$}

Craig, H., Hinckley, J. J., Winkelseth, M., Carry, L., Walley, J., Bardach, L., et al. (1993). Quantifying connected speech samples of adults with chronic aphasia. Aphasiology, 7(2), 155-163.

Doyle, P., McNeil, M., Park, G., Goda, A., Rubenstein, E., Spencer, K., Carroll, B., Lustig, A., \& Szwac, L. (2000). Linguistic validation of four parallel forms of a story retelling procedure. Aphasiology, 14(5/6), 537-549.

Folstein, J. A., Folstein, S. E., \& McHugh, P. R. (1975). "Mini-mental state": A practical method for grading the mental state for the clinician. Journal of Psychiatric Research, 12, 189198.

Kertesz, A. (1982). Western aphasia battery. New York: Grune \& Stratton.

Nicholas, L. E., \& Brookshire, R. H. (1993). Quantifying connected speech of adults with aphasia. Journal of Speech and Hearing Research, 36, 338-350.

Nicholas, L. E., \& Brookshire, R. H. (1995). Presence, completeness, and accuracy of main concepts in the connected speech of non-brain-damaged adults and adults with aphasia. Journal of Speech and Hearing Research, 38(1), 145-153.

Wright, H. H., Capilouto, G. J., \& Wagovich, S. W., Cranfill, T. B., \& Davis, J. E. (in press). A quantitative measure of adults' structured narratives: Development and reliability, Aphasiology.

Yorkston, K. M., \& Beukelman, D. R. (1980). An analysis of connected speech samples of aphasic and normal speakers. Journal of Speech and Hearing Disorders, 45, 27-36 
Table 1. Means (standard deviations) for demographic and clinical information for the aphasia and neurologically intact (NI) group

\begin{tabular}{lll} 
& Aphasia Group & NI Group \\
\hline Age (in years) & $66.5(11.2)$ & $69.4(8.3)$ \\
$\quad$ Mean (SD) & $13.0(2.8)$ & $12.5(2.8)$ \\
$\quad$ Education (in years) & & \\
$\quad$ Mean (SD) & $28.3(29.6)$ & \\
M/P CVA ${ }^{2}$ (in months) & & \\
$\quad$ Mean (SD) & $71.6(19.9)$ & \\
WAB $^{3}$ aphasia quotient & & \\
Mean (SD) & & $28.4(2.2)$ \\
MMSE $^{4}$ & & \\
Mean (SD) & & \\
\hline
\end{tabular}

Note: ${ }^{1}$ Neurologically intact group; ${ }^{2}$ Months post CVA; ${ }^{3}$ Western Aphasia Battery; ${ }^{4}$ Mini-mental status examination 
Table 2. Means (standard deviations) and ranges for proportion of main events told by the groups for picture type stimuli.

\begin{tabular}{lcccc}
\cline { 2 - 5 } & \multicolumn{4}{c}{ Group } \\
\cline { 2 - 5 } & \multicolumn{2}{c}{ Aphasia Group } & \multicolumn{2}{c}{ NI Group } \\
& Session 1 & Session 2 & Session 1 & Session 2 \\
\hline Single Picture & $.19(.17)$ & $.26(.28)$ & $.46(.25)$ & $.49(.32)$ \\
Mean (SD) & $.00-.44$ & $.00-.78$ & $.22-.78$ & $.00-.89$ \\
Range & & & & \\
Picture Sequence & $.32(.28)$ & $.38(.30)$ & $.57(.27)$ & $.61(.27)$ \\
Mean (SD) & $.00-.67$ & $.00-.73$ & $.07-.93$ & $.07-.87$ \\
Range & & &
\end{tabular}

Note: ${ }^{1}$ Neurologically intact group 
Table 3. Mean absolute differences, standard deviations (SD), and ranges between sessions and Pearson product-moment correlation coefficients (r) for the younger and older groups.

\begin{tabular}{lcc}
\cline { 2 - 3 } & \multicolumn{2}{c}{ Groups } \\
\cline { 2 - 3 } $\mathrm{ME}^{1}$ & Aphasia Group & NI Group \\
Mean & .11 & .14 \\
SD & .14 & .09 \\
Range & $.00-.34$ & $.00-.56$ \\
$\mathrm{r}$ & $.82^{*}$ & $.72^{*}$ \\
\hline
\end{tabular}

Note: ${ }^{1}$ proportion of main events calculated by dividing number of main events told by total number of main events; *significant at $\mathrm{p}<.01$ 